\title{
PRINCIPAIS SOLOS DA REGIÃO SEMIÁRIDA DO BRASIL FAVORÁVEIS AO CULTIVO DO Eucalyptus L' Heritier
}

MAIN SOILS OF THE SEMIARID REGION OF BRAZIL FOR Eucalyptus L' Heritier

\author{
Dráuzio Correia Gama ${ }^{1}$, Janisson Batista de Jesus ${ }^{2}$ \\ ${ }^{1}$ Universidade Estadual do Sudoeste da Bahia, Vitória da Conquista, Bahia, Brasil - \\ drauziogama@hotmail.com \\ ${ }^{2}$ Universidade Federal do Rio Grande do Sul, Porto Alegre, Rio Grande do Sul, Brasil - \\ janisson.eng@gmail.com
}

RESUMO

Fatores climáticos tem sido um grande empecilho para as atividades agropecuárias na região semiárida do Brasil. Pesquisas silviculturais realizadas com diferentes materiais genéticos para a produção de madeira na região têm produzido resultados satisfatórios, principalmente com o eucalipto. Entretanto, informação edáfica específica para a cultura do eucalipto no semiárido é escasso. Nesse sentido, o presente trabalho objetivou identificar os principais tipos de solos recomendados para o eucalipto na região semiárida do Brasil. Utilizou-se de revisão de literatura especializada. Dados obtidos de plataformas oficiais foram processados com uso de planilha Windows Excel 10. Mapas temáticos foram confeccionados em software Quantum GIS (3.6.0). Seis Classes de solos (Argissolos, Neossolos, Latossolos, Luvissolos, Planossolos e Cambissolos), ocupam 98\% da região semiárida do Brasil. Destes, Cambissolos, Neossolos Quartzarênicos, Latossolos e Argissolos, embora com baixa fertilidade natural, podem ser mais recomendáveis à eucaliptocultura por apresentar dentre outros atributos, relevo relativamente plano, profundidade e drenagem adequada; inexistência de camadas de impedimento e boa capacidade de armazenamento de água.

PALAVRAS-CHAVE: Atributos edáficos, Eucalipto, Silvicultura.

\begin{abstract}
Climatic factors have been a major obstacle to agricultural activities in the semiarid region of Brazil. Silvicultural research carried out with different genetic materials for the production of wood in the region has produced satisfactory results, mainly with eucalyptus. However, specific edaphic information for the eucalyptus culture in the semiarid region is scarce. In this sense, this study aimed to identify the main types of soil recommended for Eucalyptus in the semiarid region of Brazil. A specialized literature review was used. Data obtained from official platforms were processed using a Windows Excel 10 spreadsheet. Thematic maps were made using Quantum GIS software (3.6.0). Six classes of soils (Argisols, Neossols, Latosols, Luvisols, Planossols and Cambisols), occupy $98 \%$ of the semiarid region of Brazil. Of these, Cambisols, Neossols Quartzarênicos, Latosols and Argisols, although with low natural fertility, may be more recommendable to Eucalyptus culture because they present, among other attributes, relatively flat relief, depth and adequate drainage; no impediment layers and good water storage capacity.
\end{abstract}

KEYWORDS: Soil Attributes, Eucalyptus, Forestry. 


\section{INTRODUÇÃO}

A intensa radiação solar, as temperaturas altas e as chuvas concentradas e irregulares, são fatores climáticos que caracterizam a região de clima semiárido do Brasil, principalmente no Nordeste (DUQUE, 2008; AB'SABER, 1999; REBOITA et al., 2016; SANTOS et al., 2019), constituindo-se assim em condições naturais relativamente desfavoráveis às atividades agropecuárias, bem como para a silvicultura, de um modo geral (DUQUE, 2008; NOGUEIRA \& SIMÕES, 2009).

Por outro lado, a partir de 1970, a silvicultura na região semiárida ganhou destaque com algumas espécies arbóreas introduzidas. As espécies do gênero Eucalyptus L' Heritier, em especial, ganharam destaque a partir de estudos com resultados satisfatórios relacionados à plasticidade ecológica e ao potencial produtivo madeireiro, por exemplo, (DRUMOND et al., 2004; ALVES et al., 2011; SANTOS et al., 2011; SANTOS \& SANTOS, 2012a; SANTOS \& SANTOS, 2012b; GADELHA et al., 2015).

Esses conhecimentos gerados foram decisivos, portanto, a considerar a eucaliptocultura na região como a melhor alternativa energética, principalmente, em termos de rápido crescimento, volume de produção madeireira em menor tempo e maior rendimento energético; baixo custo benefício e como compensação ambiental contribuindo na redução da supressão da vegetação nativa da Caatinga (GONÇALVES, 2002; DRUMOND et al., 2004; ALVES et al., 2011; GADELHA et al., 2012; GADELHA et al., 2015; BRASIL, 2015).

Por outro lado, vale salientar que as pesquisas realizadas com essas espécies madeireiras na região de clima semiárido tem se respaldado apenas aos efeitos das variáveis climáticas no desenvolvimento vegetal, como o estresse hídrico, por exemplo, (SOUZA et al., 2006; SANTOS \& SCHUMACHER, 2016), dando menor destaque as condições edáficas e a elas diretamente relacionadas.

Nesse contexto, as espécies Eucalyptus crebra F. Muell; E. camaldulensis Dehnh, E. tereticornis Sm; E. pellita F. Muell, E. brassiana S.T. Blake, E. exserta F. Muell, E. tessellaris (F. Muell) KDHill \& LASJohnson (Corymbia tessellaris KDHill \& LASJohnson) e Eucalyptus alba Reinw (ex $\mathrm{BI}$ ), tem sido as mais indicadas para a produção madeireira na região semiárida associado ao desenvolvimento de pesquisas, sobretudo por resistir às baixas precipitações pluviométricas (GOLFARI, 1978; DRUMOND et al., 2004; ALVES et al., 2011; SANTOS et al., 2011; GADELHA et al., 2012; GADELHA et al., 2015).

Assim, de acordo com as escassas investigações edáficas de interesse para a eucaliptocultura na região semiárida do Brasil e zoneamento de sítios, por exemplo, o presente trabalho teve como objetivo identificar as principais classes de solos em termos químicos, físicos e topográficos, para o eucalipto na região de clima semiárido do Brasil.

\section{MATERIAL E MÉTODOS}

A região de clima semiárido do Brasil, delimitada pelos

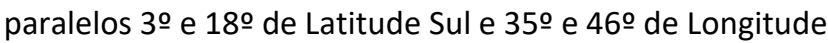
Oeste, compreende uma área de $980.132,977$ km² $^{2} 63,07 \%$ da extensão territorial do Nordeste) e uma população estimada em 23.846 .982 habitantes ( $42,44 \%$ da população do Nordeste), estendendo-se pelos territórios dos Estados do Piauí, do Ceará, do Rio Grande do Norte, da Paraíba, de Pernambuco, de Alagoas, de Sergipe e da Bahia e parte da região norte de Minas Gerais (BRASIL, 2010), podendo ser vista a delimitação dessa região de clima semiárido do Brasil na Figura 1.

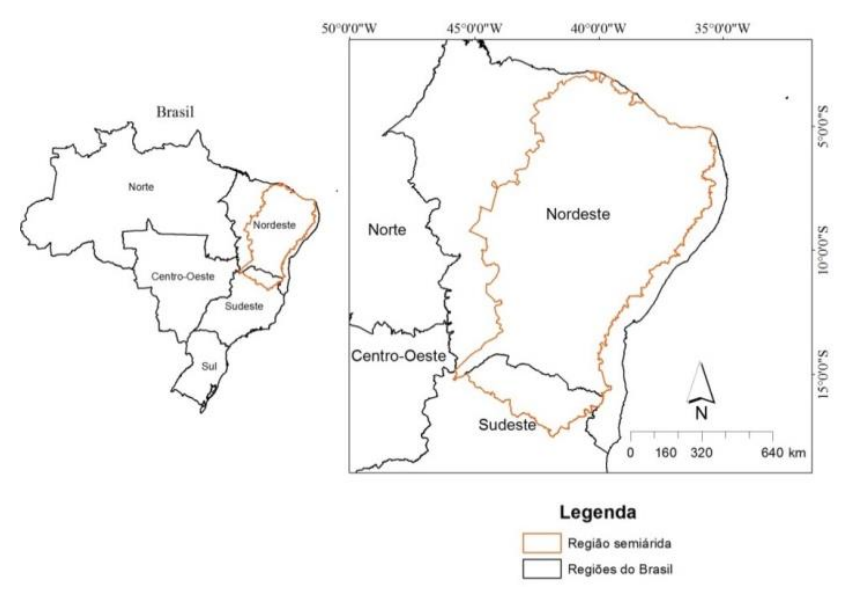

Figura 1. Mapa de localização geográfica da Região de clima semiárido do Brasil, com base nos dados do Instituto Nacional do Semiárido (BRASIL, 2010).

A geologia da região de clima semiárido nordestino, em especial, é modelada por dois tipos de estruturas, o embasamento cristalino (ocupando $70 \%$ dessa região) através das depressões interplanálticas, entremeadas por maciços antigos e chapadas esporádicas, geralmente formando solos rasos e eutróficos. $E$ as bacias sedimentares, com relevos do tipo tabuliformes, como morros e topos planos e vertentes escarpadas, geralmente com solos profundos (superiores a dois metros) com alta capacidade de infiltração, baixo escoamento superficial e boa drenagem natural (CUNHA \& GUERRA, 2003; ROSS, 2003; GIONGO et al., 2011).

A região possui clima do tipo BSw'h', conforme a 
classificação de Köppen, qualificado como tropical seco com a evaporação excedendo a precipitação, onde caracteriza-se por clima quente e seco e com duas estações definidas: seca e chuvosa. Na maior parte, as chuvas se concentram em três a quatro meses durante o ano, acarretando um balanço hídrico negativo na maioria dos meses e elevado índice de aridez (SOUZA et al., 2014).

A precipitação anual varia de $150 \mathrm{~mm}$ a $1.300 \mathrm{~mm}$ com médias oscilando entre $300 \mathrm{~mm} \cdot \mathrm{ano}^{-1}$ e $800 \mathrm{~mm} \cdot \mathrm{ano}^{-1}$. As temperaturas são relativamente elevadas, com média anual em torno de $28^{\circ} \mathrm{C}$, apresentando máxima de até $40^{\circ} \mathrm{C}$ $a_{n} o^{-1}$. Nos dias de maiores insolações, a temperatura pode ultrapassar os $45^{\circ} \mathrm{C}$ e nas áreas mais altas, pode chegar a $10^{\circ} \mathrm{C}$ ou $15^{\circ} \mathrm{C}$. A insolação média anual é de 2.800 horas com taxas médias de evaporação de $2.000 \mathrm{~mm}^{-a n o^{-1}}$. A umidade relativa do ar, em geral, é de aproximadamente $50 \%$. Nas áreas de maior altitude, as condições microclimáticas se apresentam com menores temperaturas, com médias entre $22^{\circ} \mathrm{C}_{\text {ano }}^{-1}$ e $23^{\circ} \mathrm{C}$ ano ${ }^{-1} \mathrm{e}$ com maiores umidades (RAMALHO, 2013).

Dos quatro Domínios Morfoclimáticos do Nordeste, o Sertão é o que mais caracteriza a peculiaridade dessa região de clima semiárido, seguida pelo Agreste em menor extensão (BRASIL, 2010; RAMALHO, 2013). A maior parte dessa região climática é ocupada, originalmente, pelo Domínio Fitogeográfico da Caatinga se estendendo por 76,63\% (BRASIL, 2010).

Para a realização do trabalho, utilizou-se de revisão de literatura especializada. Dados oficiais foram obtidos a partir da plataforma digital do Instituto Nacional do Semiárido (INSA) e da Empresa Brasileira de Pesquisa Agropecuária (EMBRAPA), dos quais foram confeccionados mapas temáticos com o auxílio do software Quantum GIS 3.6.0 e processados com a utilização de planilha de Excel Windows10.

\section{RESULTADOS E DISCUSSÃO}

Conforme o Sistema de Classificação de Solos do Brasil, quanto ao nível de Ordem, existem 13 classes de solos no território nacional (BRASIL, 2018) dos quais 10 são encontradas na região semiárida. Não ocorrendo, portanto, Espodossolos, Organossolos e Nitossolos.

Observa-se que a distribuição dessas classes de solos forma uma paisagem em mosaicos com algumas classes concentrando-se mais que outras em determinados enclaves.

A exemplo disso tem-se os Vertissolos localizados mais ao norte e ao sul e sudeste da região e os Planossolos mais ao centro-leste, diferentemente das classes de Latossolos,
Neossolos e Argissolos com distribuição mais homogênea na região (Figura 2).

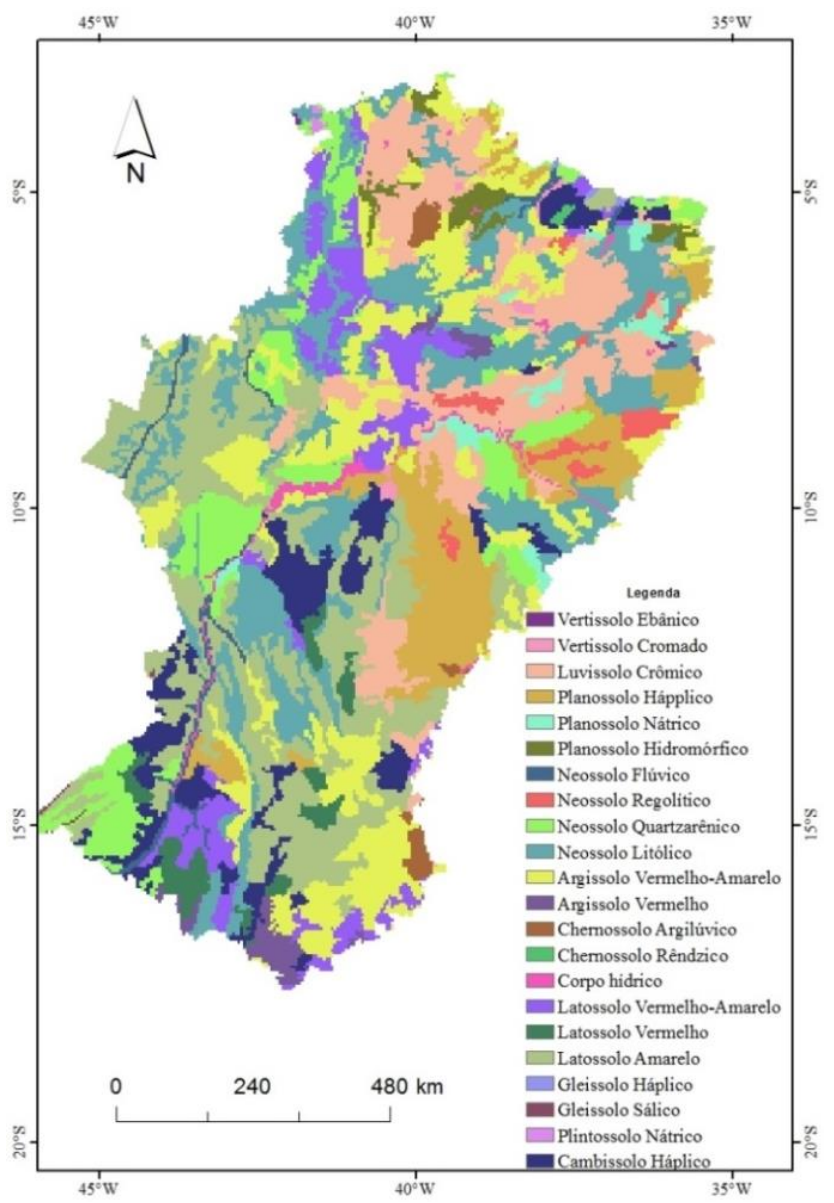

Figura 2. Distribuição das Classes de Solos existentes na região de clima semiárido do Brasil, com base nos dados do Instituto Nacional do Semiárido (BRASIL, 2010).

A distribuição espacial das classes de solos na região de clima semiárido do Brasil, marcada pela sazonalidade, decorre de fatores pedogenéticos (clima, material de origem, relevo, organismos e tempo) e condições específicos como chuvas escassas mal distribuídas e concentradas; intensas insolações e temperaturas elevadas associadas a posições topográficas distintas (cimeiras regionais, pedimentos, pavimentos detríticos, planícies aluviais, planaltos tabulares, etc) e de controles litológicos através da qualidade do material parental formador de solo (rochas de origem cristalina ou sedimentar) existente, conforme autores como Ross (2003), Corrêa et al. (2014) e Reboita et al. (2016).

Nota-se ainda que essas diferenciações tanto entre quanto dentre as classes de solos podem ser encontradas em uma mesma topossequência ao longo de um perfil topográfico, segundo Gonçalves (2002) e Corrêa et al. 
(2014). Nisso, compreende-se que essa variação dos solos existentes na região, pode ser ainda bastante complexa, quando considerada em escala de planejamento local específico, principalmente.

Em extensão territorial, predominam nessa região as classes de Neossolos ocupando 27,32\% da região, seguidas por Latossolos (25,94\%); Argissolos (15,59\%); Luvissolos $(12,18 \%)$; Planossolos (10,84\%) e Cambissolos com 6,02\% de ocupação e que juntas respondem por 97,89\% (Figura $3)$.

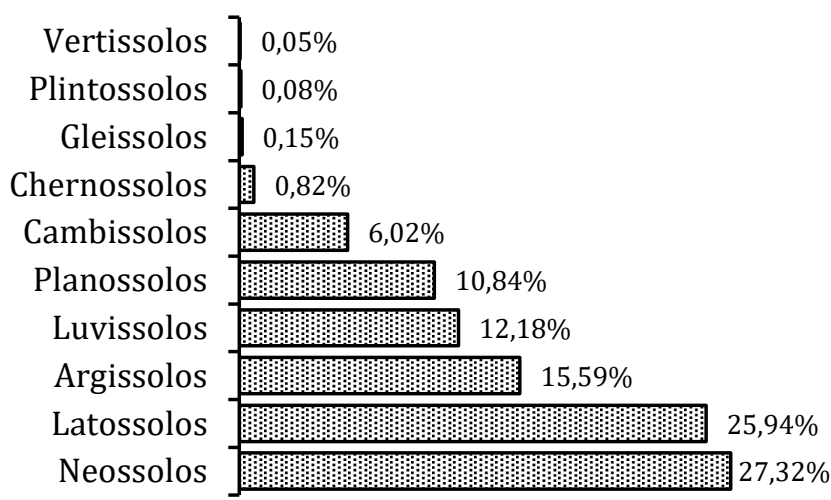

Figura 3. Distribuição das Classes de Solos na região de clima semiárido do Brasil, com base nos dados do Instituto Nacional do Semiárido (BRASIL, 2010).

Apenas três dessas classes (Neossolos, Latossolos e Argissolos), correspondem a $68,85 \%$ dos solos na região, podendo ser mais bem observado a distribuição das cinco maiores classes de solos em extensão na Figura 4.

Quanto à granulometria dos solos, prevalecem na região de clima semiárido do Brasil, principalmente no Nordeste, classes com textura arenosa a franco-arenosa e, na maioria das classes, são de pouco profundas a profundas e com relativa capacidade de armazenamento de água. Entretanto, em extensão, predominam maiores áreas com solos profundos a muito profundos, a exemplo dos Latossolos e alguns Neossolos presentes.

Considerando o aspecto químico, os solos possuem de um modo geral, baixo carbono orgânico total (COT) e baixo teor de fósforo, onde os Cambissolos e Luvissolos são as classes que apresentam maior estoque de fósforo (respectivamente, $301 \mathrm{mg} \cdot \mathrm{kg}^{-1}$ e $235 \mathrm{mg} \cdot \mathrm{kg}^{-1}$ ) e maiores teores de carbono orgânico total (respectivamente, 12,2 mg. $\mathrm{kg}^{-1}$ e 11,8 mg. $\mathrm{kg}^{-1}$ ), conforme se observa na Tabela 1.

Daí se observa uma complexa estrutura de solos possíveis em diferentes condições químicas, físicas e topográficas, principalmente quando delimitado por unidade de paisagem em uma escala local.

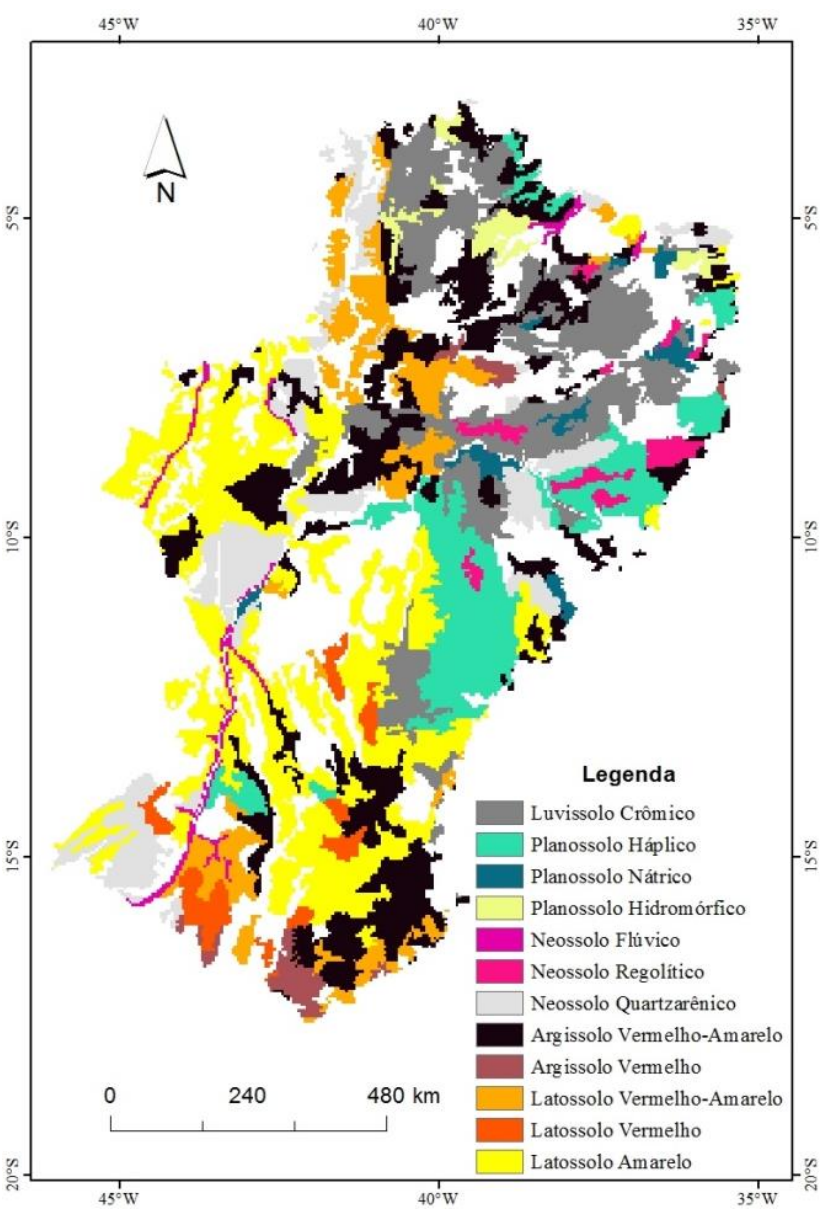

Figura 4. Distribuição das Cinco Principais Classes de Solos de maior extensão na região de clima semiárido do Brasil, com base nos dados do Instituto Nacional do Semiárido (BRASIL, 2010).

Nesse contexto, não é recomendável plantios florestais de eucalipto de alto rendimento em uma área que apresente apenas uma característica edáfica favorável.

Nota-se com isso, por exemplo, que os melhores sítios dos Latossolos e em alguns Argissolos que sustentam a maior parte dos plantios florestais de eucalipto no Brasil (GONÇALVES, 2002; LEITE et al., 2013), não se deve apenas pela coincidência de serem essas as classes de solos de maior extensão no país, mas por somar as condições edáficas favoráveis ao sucesso dos projetos florestais.

Além do mais, embora a posição topográfica, em termos de declividade, não seja um fator limitante a silvicultura de eucalipto, embora solos com topografia plana permitam a exploração mecanizada, conforme Corrêa et al. (2009), os relevos planos (0-3\%) a suaveondulados (3-8\%) são os mais indicados, conforme Gonçalves (2002), nos quais na região se encontram os Latossolos, Argissolos e Cambissolos, principalmente.

Com relação à profundidade efetiva, quanto mais profunda mais preferível são os solos, pois, conforme 
Gonçalves (2002) e Leite et al. (2013), exigem pouca mecanização, bem como contribuem para maior capacidade de armazenamento de água e melhor desenvolvimento do sistema radicular da planta.

Tabela 1. Principais atributos edáficos favoráveis à eucaliptocultura existente nas maiores classes de solos em extensão territorial, distribuídos na região de clima semiárido do Brasil.

\begin{tabular}{|c|c|c|c|c|c|c|c|}
\hline \multirow{2}{*}{\multicolumn{2}{|c|}{ Atributos }} & \multicolumn{6}{|c|}{ Classes de Solos } \\
\hline & & $*^{*} \mathrm{R}$ & $\mathrm{L}$ & $P$ & $\mathrm{~T}$ & $S$ & C \\
\hline \multirow{3}{*}{ G-\% } & Argila & 8,4 & 25,0 & 14,7 & 17,6 & 10,5 & 29,5 \\
\hline & Silte & 18,0 & 13,0 & 15,7 & 25,8 & 18,8 & 21,2 \\
\hline & Areia & 73,6 & 62,0 & 69,6 & 56,6 & 70,7 & 49,3 \\
\hline COT & g. $\mathrm{kg}^{-1}$ & 7,6 & 9,7 & 8,9 & 11,8 & 7,4 & 12,2 \\
\hline$P$ & $\mathrm{mg} \cdot \mathrm{kg}^{-1}$ & 170 & 173 & 167 & 235 & 162 & 301 \\
\hline \multirow{3}{*}{ Prof } & $\mathrm{Pp}$ & $x$ & & & $x$ & $x$ & $x$ \\
\hline & $\mathrm{Pf}$ & & & $x$ & & & $x$ \\
\hline & $\mathrm{Mp}$ & & $x$ & & & & \\
\hline \multicolumn{2}{|c|}{ Mecanização } & $M L$ & MNL & MNL & $M L$ & $\mathrm{ML}$ & $M L$ \\
\hline \multicolumn{2}{|c|}{ CAA } & $A B$ & $A$ & $A$ & A & B & $A$ \\
\hline
\end{tabular}

$\mathrm{R}=$ Neossolos; $\mathrm{L}=$ Latossolos; $\mathrm{P}=$ Argissolos; $\mathrm{T}=$ Luvissolos; $\mathrm{S}=$ Planossolos; $\mathrm{C}=$ Cambissolos; $\mathrm{G}-\%$ = granulometria; $\mathrm{COT}=$ carbono orgânico total; $\mathrm{P}=$ fósforo; Prof. = Profundidade do solo; $\mathrm{Pp}=$ pouco profundo $(<50 \mathrm{~cm}) ; \mathrm{Pf}=$ profundo $(50 \mathrm{~cm}-100 \mathrm{~cm}) ; \mathrm{Mp}=$ muito profundo $(>100 \mathrm{~cm}) ; \mathrm{ML}=$ mecanização limitada $(60 \%$ dos solos em média $)$; MNL = mecanização não-limitada $(60 \%$ dos solos em média); $\mathrm{CAA}=$ capacidade de armazenamento de água; $\mathrm{A}=$ alta (quando mais de $50 \%$ do solo em média); $B$ = baixa (quando mais de $50 \%$ do solo em média). *Neossolos $=$ valores médios entre os Neossolos regolíticos, litólicos, quartzarênicos e flúvicos.

Fonte: adaptado de Gonçalves (2002), Brasil (2010), Cunha et al. (2010), Giongo et al. (2011) e Brasil (2018).

Características essas que são encontradas na região de clima semiárido do Brasil em classes de Latossolos e Neossolos (com exceção dos Neossolos litólicos) e Argissolos com horizontes superficiais mais espessos (a depender da posição topográfica), que podem ser mais profundos (Tabela 1).

Em Argissolos menos espessos, a perda de água por evaporação superficial pode ser mais intensa, além do horizonte diagnóstico B textural, existente em alguns desses solos, diminuir a velocidade de infiltração de água. Para Sales et al. (1999), a velocidade de infiltração em Latossolos é maior que Argissolos na profundidade até 20 $\mathrm{cm}$, sendo maior em Argissolos entre $60-80 \mathrm{~cm}$.

Entretanto, González \& Alves (2005) explicam que horizonte $B$ textural relacionado a uma profundidade de menor influência dos fatores climáticos, regula a evaporação da água nas camadas superficiais do solo.

E devido à diferença de textura dos horizontes superficiais para os subsuperficiais, isso tende a contribuir para o maior armazenamento de água nas camadas mais profundas e, conseqüentemente, ocorre menor perda por evaporação a partir dos $60 \mathrm{~cm}$ em média de profundidade, ainda segundo os autores.

Dalmago et al. (2010), ressalta que a evaporação com a secagem mais rápida da camada superficial do solo se explica em razão da condutividade hidráulica não saturada do solo diminuir na medida em que o solo seca nessa camada, pelo aumento da inversão da taxa de evaporação de solos, principalmente em plantios convencionais. Uma vez que, segundo Zwirtes et al. (2011), solos sob plantios diretos possuem maiores velocidades de infiltrações básica que plantios convencionais, inferiores apenas quando comparado a áreas de vegetação nativa.

Ainda segundo González \& Alves (2005) solos que apresentam mudança textural abrupta, apresentam compacidade natural em alguns níveis do subsolo.

Quanto aos Planossolos e Luvissolos, estes dificultam a absorção da água, ambos estimulando o escoamento superficial, segundo autores como Cunha et al. (2010), Corrêa et al. (2014) e Souza \& Paula (2019).

Deve-se levar em conta, que a capacidade de armazenamento de água dos solos na região de clima semiárido apresenta diferenciações entre os solos, por estes responderem, conforme Corrêa et al. (2014), a distintas condições edáficas em função da pedogenética atrelada a fatores pedoclimáticos quanto a profundidades e espessuras na distribuição das frações granulométricas nos horizontes do solo.

Ressalta Poggiani (1982) que em solo de textura arenosa, infiltra-se mais água e quando ocorre perda de água, os primeiros cinco centímetros representam apenas $10 \%$ da água armazenada.

Giongo et al. (2011) enfatiza que em todos os solos da região semiárida, mesmo os mais argilosos, a fração areia é maior do que as frações argila e silte, a qual apresenta tendência de maior permeabilidade e logo maior infiltração de água, mas não necessariamente maior armazenamento. Onde para Salviano et al. (2016) esse predomínio de areia, principalmente areia fina, torna-se uma característica física favorável aos solos no sentido de reduzir a percolação da água e aumentar sua retenção e disponibilidade, compensando os baixos teores de silte e argila.

Em solos mais pedregosos, segundo Poggiani (1982), a evaporação pode ser muito reduzida com pouca água perdida, desde que sob uma cobertura vegetal mais densa, contribuindo em maior armazenamento e reduzido escoamento superficial, uma vez que a água infiltrada encontra-se mais protegida de fatores climáticos, como radiação solar, por exemplo.

Corrêa et al. (2014) chamam atenção para solos de origem cristalina que por serem pouco espessos, são 
altamente vulnerável a erosão e ao escoamento superficial difuso, predominando com essa característica os Neossolos (litólicos e regolíticos) ou os mais desenvolvidos dos embasamentos cristalinos como os Luvissolos e Planossolos.

Ressalvam-se ainda algumas peculiaridades a respeito da pouca profundidade em algumas classes de solos por apresentarem camadas de impedimento (alguns Neossolos e Cambissolos); solos argilosos com elevada plasticidade a pegajosidade (Luvissolos e Chernossolos) conforme Gonçalves (2002), Brito et al. (2017) e Ramalho \& Guerra (2018). E a presença de fragmentos de rochas (Planossolos e alguns Neossolos), conforme Souza e Paula (2019) os quais são características que reduzem a mecanização na eucaliptocultura, sendo os Latossolos, Argissolos e os Neossolos Quartzarênicos os mais favoráveis nesse sentido, por exemplo.

Com relação à fertilidade natural, os solos na região de clima semiárido em sua grande maioria são distróficos, principalmente em Latossolos e Argissolos na profundidade de 0-20, conforme Silva et al. (2018).

Fato é que aproximadamente $76 \%$ da extensão territorial da região semiárida do Brasil são formados por solos distróficos de baixa fertilidade natural (44,3\%) a muito baixa (31,34\%), sendo $17,7 \%$ com média a alta fertilidade e de apenas 6,29\% dessa área do semiárido com alta fertilidade (BRASIL, 2010). Sendo que, segundo Salviano et al. (2016), baixos teores de cátions trocáveis estão relacionados à natureza do material de origem.

Dentre os macronutrientes essenciais ao desenvolvimento vegetal, o fósforo nas formas de fosfatos $\left(\mathrm{PO}_{4}{ }^{3-}\right)$ é o mais limitante ao crescimento da planta, requerido em níveis mais elevados, principalmente para o rápido estabelecimento do sistema radicular na fase inicial de crescimento, decrescendo a demanda com o aumento da idade da planta (BARROS et al., 2000; BARROS et al., 2013; DIAS et al., 2015; SALVIANO et al., 2016), onde nos solos da região de clima semiárido é um nutriente encontrado com baixos teores, conforme autores como Corrêa et al. (2009), Souza et al. (2010) e Gionco et al. (2011).

Porém, a maior concentração de fósforo inorgânico nessa região provém dos solos de origem cristalina, segundo Salcedo et al. (2006). Tendo a matéria orgânica (MO), ainda segundos os autores, como a principal fonte de fósforo orgânico, respondendo de $30 \%$ a $60 \%$ do fósforo no ecossistema, uma vez que quanto menor o fósforo inorgânico (Pi), maior a contribuição da matéria orgânica no fornecimento de $P$.

Por outro lado, a decomposição de $\mathrm{MO}$ nessa região é caracterizada de um modo geral lenta por ocorrência da baixa precipitação, embora sob altas temperaturas, segundo Holanda et al. (2015). O que causa, de certa forma, baixa concentração do fósforo no solo que, ainda, pela sua baixa mobilidade e fixando-o em sua maior parte na argila (BARROS et al., 2000), torna-se relativamente pouco disponível para as plantas em condições de fertilidade natural conforme Barros et al. (2000) e Gionco et al. (2011).

Considerando-se, segundo Corrêa et al. (2014), que todos os solos estão sob um regime de temperatura e umidade muito semelhante, os Vertissolos, os Cambissolos e os Luvissolos são as classes que apresentam maior estoque de fósforo em ambientes naturais e os Vertissolos e os Cambissolos maiores teores de carbono orgânico total conforme Gionco et al. (2011), contribuindo dessa maneira em maior armazenamento de água na superfície do solo e maior capacidade de troca de cátions (CTC) com oferta de nutrientes a médio e longo prazo.

Estudando solos arenosos do semiárido, Corrêa et al. (2009), também observaram baixos valores de outros nutrientes, como Ca (cálcio) e Mg (magnésio), até a profundidade de $60 \mathrm{~cm}$, notando que os teores desses cátions tiveram considerável aumento nas áreas com diferentes usos agrícolas e ciclos, uma vez que a fertilidade do solo foi melhorada com o manejo adotado.

O potássio $(\mathrm{K})$, também é um dos nutrientes mais requeridos na fase de crescimento da planta, embora exigentes em níveis mais baixos (BARROS et al., 2000), entretanto é o segundo nutrientes que mais limita a obtenção de altas produtividades, conforme Barros et al. (2013). Pela tolerância a solos ácidos, o Ca e Mg são nutrientes menos requeridos e em níveis baixos, administrado com vistas apenas a suprir as necessidades das plantas (BARROS et al., 2000; 2013).

De um modo geral, Barros et al. (2000) destacam que com o aumento da idade, há uma reversão dessa demanda e camadas mais profundas do solo passam a ser exploradas.

Vale salientar ainda que as características químicas dos solos do seminário e o material genético utilizado, devem ser levados em consideração quando do momento da administração de fertilizantes, tanto avaliando o nível crítico de implantação (teor necessário de nutriente no solo aos primeiros meses de plantio), quanto ao nível crítico de manutenção (teor necessário de nutriente no solo para manter certa produtividade durante o ano), a fim de obter resultados satisfatórios de produtividade, conforme Barros et al. (2013).

Desse modo, Corrêa et al. (2009) destacam, 
principalmente em solos de textura arenosa e de baixa fertilidade natural, a necessidade de realizar o manejo do solo com grande foco na matéria orgânica, de forma que contribuam com o aumento dos teores de nutrientes, a fim de melhorar sua qualidade. Principalmente quanto a disponibilidade do nitrogênio $(\mathrm{N})$ do solo para a planta, através da ciclagem de nutrientes, uma vez que este é o nutriente mais acumulador em povoamento florestal, conforme Barros et al. (2013).

Não obstante, a fertilidade natural de um solo é sempre desejável para o sucesso de uma atividade agrocultural com baixo custo e alta produtividade, entretanto a ausência dessa fertilidade natural, principalmente considerando a silvicultura, pode ser suprida por meio de adubação (DIAS et al., 2015).

Nesse sentido, Corrêa et al. (2009) assinalam que a baixa fertilidade dos solos do semiárido torna imprescindível a aplicação de fertilizantes para o alcance de produções satisfatórias, ressalvando que, devido a baixa CTC desses solos, as adubações devam ser parceladas, de forma a evitar saturação do complexo sortivo, minimizando as perdas por lixiviação e consequentemente os riscos de contaminação do lençol freático e de reservatórios de água mais próximos.

Além de que, após a implantação florestal, o manejo dos resíduos madeireiros deixados após uma colheita, por exemplo, torna-se imprescindível a contribuir, através dos processos de ciclagem de nutrientes, no aumento dos estoques de nutrientes dos sítios de plantios, evitando o seu esgotamento, conforme Leite et al. (2013).

Ademais, a alta eficiência e a baixa exigência nutricional do eucalipto em comparação à cultura agrícola, também contribuem de certa forma à viabilidade dessa silvicultura em solos distróficos (SANTANA et al., 2002; DIAS et al., 2015).

Desse modo são relevantes essas características de manejo e fertilidade do solo, o que tornam imprescindíveis a serem consideradas quanto a implantações, ao manejo silvicultural e a rotações do eucalipto, sempre quando for o caso, em regiões de clima semiárido no Brasil.

\section{CONCLUSÕES}

Os principais solos identificados para a silvicultura de eucalipto na região de clima semiárido do Brasil, em termos químicos, físicos e topográficos, são os Cambissolos, Latossolos e Argissolos por possuírem relevo relativamente plano, profundidade e drenagem adequada; inexistência de camadas de impedimento (solos mecanizáveis), além de boa capacidade de armazenamento de água. E os Neossolos (quartzarênicos), embora estes com baixa capacidade de armazenamento de água.

\section{REFERÊNCIAS}

$A B^{\prime} S A B E R, A . N$. Sertões e sertanejos: uma Geografia humana sofrida. Estudos Avançados: Dossiê Nordeste Seco, 1999.

ALVES, A.M.C. et al. Quantificação da produção de biomassa em clones de eucaliptos com 4, 5 anos, no polo gesseiro do AraripePE. Revista de Ciências Agrárias, v.48, n.1, p.161-174, 2011.

BARROS, N.F. et al. Nutrição e Adubação Mineral de Eucalipto. Eucaliptocultura no Brasil: silvicultura, manejo e ambiência. Viçosa: SIF, 2013.

BARROS, N.F. et al. Recomendação de fertilidade minerais em plantios de eucalipto. Nutrição e Fertilização Florestal. IPEF: Piracicaba, 2000.

BRASIL. Acervo digital geográfico e populacional do semiárido nordestino. Instituto Nacional do Semiárido e Sistema de Gestão da Informação e do Conhecimento do Semiárido Brasileiro INSA/SIGSAB, 2010. Disponível em: http:// http://sigsab.insa.gov.br/acervoDigital

BRASIL. Sistema Brasileiro de Classificação de Solos (SiBCS). 5.ed. Embrapa: Brasília, 2018.

BRITO, R.F.D. et al. Morfologia e fertilidade do solo em áreas de produção do semiárido. Revista de Ciências Agrárias, v.40, n.3, p.525-532, 2017.

CORRÊA, A.C.B. et al. Solos do ambiente semiárido brasileiro: erosão e degradação a partir de uma perspectiva geomorfológica. Degradação dos solos no Brasil. Rio de Janeiro: Bertrand Brasil, 2014.

CORRÊA, E.A. et al. Qualidade física de solos arenosos submetidos a diferentes usos da terra. Revista Brasileira de Geografia Física, v.9, n.5, p.1501-1512, 2016.

CORRÊA, R.M. et al. Atributos químicos de solos sob diferentes usos em perímetro irrigado no semiárido de Pernambuco. Revista Brasileira de Ciência do Solo, v.33, p.305-314, 2009.

CUNHA, S.B.; GUERRA, A.J.T. Geomorfologia do Brasil. 3.ed. Rio de Janeiro: Bertrand Brasil, 2003.

CUNHA, T.J.F. et al. Principais solos do semiárido tropical brasileiro: caracterização, potencialidades, limitações, fertilidade e manejo. Semiárido brasileiro: pesquisa, desenvolvimento e inovação. Petrolina: Embrapa Semiárido, 2010.

DALMAGO, G.A. et al. Evaporação da água na superfície do solo em sistemas de plantio direto e preparo convencional. Pesquisa Agropecuária Brasileira, v.45, n.8, p.780-790, 2010.

DIAS, L.P.R. et al. Eficiência relativa de fosfatos naturais na adubação de plantio de mudas de Eucalyptus dunnii Maiden e 
Eucalyptus benthamii Maiden Et Cambagem em solo sem e com calagem. Ciência Florestal, v.25, n.1, p.37-48, 2015.

DRUMOND, M.A. et al. Contribuição da Embrapa Semiárido para o desenvolvimento dos sistemas agroflorestais no Semiárido brasileiro. Agrossilvicultura, v.1, n.2, p.145-153, 2004.

DUQUE, G. Conviver com a seca: contribuição da articulação do semiárido ao desenvolvimento sustentável. Desenvolvimento e Meio Ambiente, n.17, p.133-140, 2008.

GADELHA, F.H.L. et al. Produtividade de clones de eucaliptos em diferentes sistemas de manejo para fins energéticos. Pesquisa Florestal Brasileira, v.35, n.83, p.263-270, 2015.

GADELHA, F.H.L. et al. Rendimento volumétrico e energético de clones de híbridos de Eucalyptus sp. no polo gesseiro do Araripe, PE. Ciência Florestal, v.22, n.2, p.331-341, 2012.

GIONGO, V. et al. Carbono no sistema solo-planta no semiárido brasileiro. Revista Brasileira de Geografia Física, v.6, p.12331253, 2011.

GONÇALVES, J.L.M. Principais solos usados para plantações florestais. Conservação e cultivo de solos para plantações florestais. Piracicaba: IPEF, 2002.

GONZÁLEZ, A.P.; ALVES, M.C. Armazenamento de água e densidade do solo sob três condições de superfície, em um Cambissol gleico de Lugo, Espanha. Revista brasileira de engenharia agrícola e ambiental, v.9, n.1, p.45-50, 2005.

HOLANDA, A.C. et al. Decomposição da serapilheira foliar e respiração edáfica em um remanescente de Caatinga na Paraíba. Revista Árvore, v.39, n.2, p.245-254, 2015.

LEITE, F.P. Conservação do solo e água. Eucaliptocultura no Brasil: silvicultura, manejo e ambiência. Viçosa: SIF, 2013.

NOGUEIRA, F.R.B.; SIMÕES, S.V.D. Uma abordagem sistêmica para a agropecuária e a dinâmica evolutiva dos sistemas de produção no nordeste semiárido. Revista Caatinga, v.22, n.2, p.16, 2009.

POGGIANI, F. O reflorestamento no Nordeste brasileiro: consequências ecológicas. Série Técnica IPEF, v.3, n.10, p.85-98, 1982.

RAMALHO, M.F.D.J.L.; GUERRA, A.J.T. O risco climático da seca no semiárido brasileiro. Territorium, v.25, p.61-74, 2018.

RAMALHO, M.F.D.J.L. A fragilidade ambiental do Nordeste brasileiro: o clima semiárido e as imprevisões das grandes estiagens. Sociedade e Território, v.25, n.2, p.104-115, 2013.

REBOITA, M.S. et al. Causas da semiaridez do sertão nordestino. Revista Brasileira de Climatologia, v.19, p.254-277, 2016.

REZENDE, L.V.B. et al. O eucalipto resseca o solo? mito ou verdade? Revista Internacional de Ciências, v.1, n.1, p.19-38, 2011.

ROSS, J.L.S. Os fundamentos da geografia da natureza. 4. ed; São Paulo: Editora da Universidade de São Paulo, 2003.
SALCEDO, I.H. Biogeoquímica do fósforo em solos da região Semiárida do Nordente do Brasil. Revista Geografia, v.23, n.3, p.159184, 2006.

SALES, L.E.O. et al. Estimativa da velocidade de infiltração básica do solo. Pesquisa Agropecuária Brasileira, v.34, n.11, p.20912095, 1999.

SALVIANO, A.M. et al. Potencialidades e Limitações para o uso agrícola de solos arenosos na região semiárida da Bahia. Magistra, v.28, n.2, p.137-148, 2016.

SANTANA, R.C. et al. Eficiência nutricional e sustentabilidade da produção em procedências de Eucalyptus grandis e Eucalyptus saligna em sítios florestais do Estado de São Paulo. Revista Árvore, v.26, p.447-457, 2002.

SANTOS, F.R.; SANTOS, M.J.C. Avaliação do desenvolvimento inicial de espécies florestais de uso múltiplo no semiárido Sergipano. Scientia Plena, v.8, n.4, p.1-4, 2012b.

SANTOS, F.R.; SANTOS, M.J.C. Avaliação do ganho de peso de ovinos santa inês mantidos em sistema silvipastoril no semi-árido nordestino. Scientia Plena, v.8, n.4, p.1-5, 2012a.

SANTOS, K.F.; SCHUMACHER, M.V. Ecofisiologia e crescimento de Eucalyptus em condição de déficit hídrico. Revista Ecologia e Nutrição Florestal, v.4, n.2, p.33-44, 2016.

SANTOS, P.M. et al. Mudanças Climáticas Globais e a Pecuária: Cenários Futuros para o Semiárido Brasileiro. Revista Brasileira de Geografia Física, v.4, n.6, p.1176-1196, 2011.

SANTOS, S.R.Q. et al. Avaliação de dados de precipitação para o monitoramento do padrão espaço-temporal da seca no Nordeste do Brasil. Revista Brasileira de Climatologia, v.25, p.80-100, 2019.

SILVA, W.T.M. et al. Levantamento da textura do solo e da relação silte/argila em regiões semiáridas do Nordeste. Agropecuária Científica no Semiárido, v.14, n.4, p.266-272, 2018.

SOUZA, F.R.C.; PAULA, D.P. Análise de perda do solo por erosão na Bacia Hidrográfica do Rio Coreaú (Ceará-Brasil). Revista Brasileira de Geomorfologia, v.20, n.3, p.491-507, 2019.

SOUZA, M.J.H.D. et al. Disponibilidade hídrica do solo e produtividade do eucalipto em três regiões da Bacia do Rio Doce. Revista Árvore, v.30, n.3, p.399-410, 2006.

SOUZA, M.T.S. et al. Caracterização climática e o efeito do estresse hídrico sob as plantas nativas da caatinga. PUBVET, v.8, n.1, p.1-17, 2014.

SOUZA, R.V.CC. et al. Caracterização de solos em uma topoclimossequência no maciço de Triunfo - sertão de Pernambuco. Revista Brasileira de Ciência do Solo, v.34, p.12591270, 2010.

ZWIRTES, A.L. et al. Caracterização físico-hídrica de solos submetidos a diferentes manejos. Applied Research \& Agrotechnology, v.4, n.3, p.51-66, 2011.

Recebido em 25-12-2019 Aceito em 10-03-2020 